\title{
Nicanor Parra en el territorio del lenguaje
}

\author{
An d RÉs G allardo
}

Universidad de Concepción, Chile

E-mail: agallard@udec.cl

(A Ivette M alverde en memoria persistente)

\section{Resumen}

Se intenta mostrar cómo el lenguaje, concretamentela lengua castellana coloquial chilena, es una fuente primaria de identidad en el poeta N icanor Parra, y base de la elaboración de sus textos. Los puntos de vista propuestos se concretan en el análisis de dos poemas: la "E popeya de Chillán", de retórica altisonante, insegura einmadura, y " $\mathrm{H}$ ay un día feliz", donde la plenitud poética cuaja en la incorporación del coloquio como lenguaje poético.

Palabras claves: 0 ralidad/escritura, identidad lingüística, antipoesía, retórica.

\section{Abstract}

Theauthor points out how language, specifically, the poet $\mathrm{N}$ icanor Parra's coloquial $\mathrm{C}$ hilean Spanish, is a primary source of cultural identity, and lies at the basis of his textual constructions. The proposed points of veiw are specified in the analysis of two poems: "Epoyeya de C hillán", from the Parra's youth, insecure and inmature in its high-sounding rhetorical approach, and " $\mathrm{H}$ ay un día feliz", a sound piece of poetry where coloquial style becomes true poetic language.

Keywords: 0 rality/writing, language identity, antipoetry, rhetoric.

Recibido: 31-07-2003. Aceptado: 24-09-2003.

- TEM PRAN AM EN TE la crítica literaria se hizo cargo del carácter profundaLmente chileno de $\mathrm{N}$ icanor Parra, al punto de llegar a considerarlo algo así como un ícono de la identidad nacional.

Una mirada somera a su producción parece avalar esta apreciación, en el sentido de que en ella encontramos, por doquier, elementos explícitos e implícitos que se nos aparecen como especialmente chilenos. En Poemas y antipoemas 
(1954), la temática de muchos poemas es voluntariamente nacional (no necesariamente nacionalista) y aun local, así como la presencia del coloquio chileno no es ya tangencial, en la forma de al usiones, sino elemento central de la estructuración del texto. Algo similar, y aun más explícito, sucede en La cueca larga (1958), donde

el poeta trata de asir las costumbres de su país y para lograrlo no encuentra nada mejor que condicionar el sesgo de la suya a la poesía popular. Q uien ha podido realizar esta acción de manera tan noble parece estar animado por el sabor nacionalista de su país, aquel que viene desde los tiempos más antiguos (Campaña, 1995: 47).

D eal gún modo, un libro bastante posterior, como los Sermonesy prédicasdel Cristo de Elqui (desde 1977), continúa este ahondamiento en la cultura tradicional desde una voz buscadamente popular. Pero ya en Versos de salón (1962), en plena vertiente antipoética, se incorpora de modo muy explícito el tema urbano, con el consiguiente empaque idiomático culto -e inculto- informal chileno, cosa que se exacerba en los Artefactos (1972). Y en los últimos años, el poeta ha transformado en un verdadero género literario (entre poético, épico, satírico y didáctico) el "discurso de sobremesa" (los dos casos más notables son el Discurso de Guadalajara (1990) y el D iscurso del Bío-Bío (1996)), manifestación de la cultura tradicional semiurbana y semipueblerina, semiletrada y semioral, pero en todo caso manifestación de una retórica plenamente chilena y que, de paso, instala al poeta como uno de los grandes escritores nacionales. Esta retórica parriana, afincada en la versión chilena de la lengua castellana, que deviene así verdaderamente "lengua nacional", es una construcción cultural sumamente compleja. Así lo resume, muy adecuadamente, M ario Rodríguez (1996: 13-14):

La lengua nacional para Parra es un "corredor de voces"..., una mezcolanza que no se puede reducir a la mistificación de un solo registro. En este sentido, en el de la hibridez de la lengua, Parra es nuestro gran poeta nacional, por encima de Huidobro, que desnacionaliza la lengua y $\mathrm{N}$ eruda que, preferencialmente, la usa en sus registros mayores.

2. La afirmación de la chilenidad de N icanor Parra apunta, en realidad, a una situación que va mucho más allá que lo meramente anecdótico. Este rasgo, que podría pensarse común a muchos otros escritores nuestros, en el caso de Parra es, quizás, el componente central de su identidad como persona y como poeta. Como se ha señalado, "Parra explicita marcas identitarias, entre ellas las de procedencia local y nacional, en distintos discursos y códigos de su poesía" (Araya, 2000: 69). 
En su vivencia provinciana chilena, y fundamentalmenteen el lar chillanejo, se halla la clave íntima que sirve de punto de partida y dellegada de la construcción y desarrollo del mundo poético de N icanor Parra:

Poco a poco, y trabajosamente, fue comprendiendo que en ese pasado, en las imágenes que retienen y reproducen el conflicto de experiencias fundamentales, estaba el tema secreto de su poesía (M orales, 1972: 12).

Lo anterior, esto es, que la profundidad de la vivencia provinciana se instaure "en raíces identitarias de su audaz proyecto literario: la antipoesía" (A raya, 2000: 33), todavía podría parecer anecdótico. D espués de todo, como ya he señalado, muchos escritores chilenos han hecho cuestión, en susobras, desu condición de tales.

¿Q ué hay, entonces, de tan especial en la chilenidad, o en la "chillanejidad" deN icanor Parra? En primer lugar, insistamos, está el hecho de quetales condiciones son parte de la fibra íntima de su trabajo poético. En segundo lugar, el hecho de que hablamos de la obra poética, no de la persona del poeta, de sus temas, de sus obsesiones, de sus intenciones. En efecto, muchas veces nos topamos con textos que tienen como tema explícito aspectos centrales o marginales dela identidad chilena, pero ello no los convierte en más que manifestación de una tradición retórica, o en declaraciones patrióticas emotivas o satíricas, 0 incluso en declaración de principios. D e algún modo, eso fue lo que sucedió con la tradición criollista, que en último término se agotó en una designación 0 mostración de elementos real o supuestamente constitutivos de una identidad, pero no en textos que se construyeran como tales desde esa identidad. Así lo ha visto M auricio O stria (1988: 60):

D escubierto el lenguaje como recurso caracterizador de mundo, los narradores regionalistas - influidos por una estrecha idea de regional ismo lingüísticoquisieron incluir en estos relatos cuantos términos populares o indígenas tuviesen a mano, dificultando muchas veces la lectura, limitando las dimensiones y perspectivas del mundo narrado y convirtiendo los textos, frecuentemente, en verdaderos catálogos de regionalismos.

(Recordemos la anécdota quetrae a colación Borges, cuando hace notar que en el Corán, el libro árabe por excelencia, no hay camellos, y luego reflexiona que si M ahoma hubiera sido un falsario, 0 un nacionalista árabe, sin duda habría prodigado caravanas de camellos por las páginas del libro. Cf. Borges, 1966, pp. 156-157).

Así pues, Parra no habla de Chile, o de Chillán; habla desde C hile o desde Chillán, como chileno y como chillanejo. Sus poemas maduros no son sobre 
Chile o sobreC hillán, son poemas chilenos o chillanejos y no pueden ser entendidos si no se tiene ello en cuenta. El "color local" no tiene cabida en ellos. Esto es crucial: cuando se habla o se escribe sobre o desde una identidad, se está procediendo, normalmente, en nombre de principios externos, y por ende, en una actitud casi fundamentalista, se buscarán elementos que, explícitamente, simbolicen lo que se concibe como tal identidad. Cuando simplemente se es, esto es, cuando se vive una identidad, no se asume, militantemente, como misión el proyecto de describir y expresar lo que se es. Q uien habla desde sí mismo, habla con su propia voz acerca de la aldea 0 acerca del ancho mundo ( $D$ on Q uijote, una vez más nos ha dejado una lección: cuando se le representó lo absurdo de que quisiera ser caballero andante, simplemente respondió "yo sé quien soy... y sé que puedo ser no sólo los que he dicho, sino los doce pares de Francia y aun todos los nueve de la fama" (D on Q uijote: I, 5).

3. Nicanor Parra puede, pues, hablando desde sí mismo, chileno chillanejo, hablar de lo quequiera, o incluso hablar desde quien quiera (por ejemplo, desde el buen ladrón o desde D omingo Zárate), porqueno hay peligro de desdibujarse, identitariamente hablando. Por eso mismo, y esto es también importantísimo, enraíza su trabajo poético en fuentes diversas, como la poesía culta hispánica, la tradición shakespeareana o whitmaniana, o bien habla desde la reflexión filosófica y científica o desde el dinamismo exuberante del coloquio, porque su pie dra angular está en la tradición oral no interrumpida, popular, religiosa y blasfe ma, metafísica y humorística. Este es el sentido profundo sobre el cual hallama do la atención, lúcidamente, I vette M alverde: el entronque de Nicanor Parra con el viejo, pero siempre vital espíritu carnavalesco, que es, por esencia, y precisamentepor partir desdeuna solidez identitaria, una actitud cultural integradora delo culto y lo popular, lo oral y lo escrito, "Ia convención poética y su transgresión, la ley y la antiley" (M alverde, 1988: 92). No se trata, por cierto, de un "carnaval" en el sentido histórico riguroso, sino del espíritu carnaval esco en un sentido funcional, esto es, en el sentido del entronque con el espíritu de la poe sía popular y del patrimonio idiomático y de la celebración gozosa e integrada del mero existir. Como en tantas ocasiones, M orales (1972) fue un pionero en entender este aspecto dela producción poética de Parra, al ligarla con el espíritu medieval, mediante su entronque con los rasgos más característicos de la poesía popular, tales como el humor "áspero, arcaizante" (cf. p. 13).

4. Ahora bien, en todo este complejo conjunto de elementos aparentemente dispares que es la poesía de Parra, hay un aspecto que asegura su unidad y su funcionamiento como sistema cultural. Este aspecto es el lenguaje. A través de su lengua castellana, tal como se ha desarrollado en Chile, Parra es Parra, esto es, 
encuentra su centro cultural y su individualidad. Aquí también hay dos carriles funcionales que es necesario explicitar.

El primer aspecto es el entronque dela poesía de Parra con la lengua culta, lo queresulta evidente: el poeta conoce su tradición, conocela retórica de la poesía culta (domina el alejandrino y el endecasílabo), ha internalizado una sintaxis y un léxico letrados, así como un sistema de actitudes propio del nivel más estandarizado, como es una extraordinaria conciencia de las normas lingüísticas, una leal tad explícita a las codificaciones intelectualizadas, etc. Pero, como se ha dicho ya, $\mathrm{N}$ icanor Parra, culto y refinado, enraíza voluntariamente su actuación lingüística en la tradición viva, es decir, con la lengua oral, con el coloquio. Eso sí, así como el espíritu carnavalesco es presencia funcional y no formal en su producción, la oralidad es motor funcional en su construcción textual, que en sí mismo no es oral propiamente. La oralidad es, así, un componente esencial, pero consciente. U na vez más, Leonidas M orales fue un adelantado al entenderlo así:

Junto con tomar conciencia del oficio de poeta y darse cuenta de su ubicación en el mundo como sujeto histórico, el modelo de su lenguaje histórico: el lenguaje hablado, se eleva a la categoría de un principio estético (M orales, 1972: 40).

I vette $M$ al verde ha ahondado todavía más en este punto, señalando que esos textos parrianos, coloquiales y aparentemente orales, de hecho son textos de un poeta culto que es consciente de lo que hace, consciente de que sus verdaderos destinatarios son lectores, esto es, miembros cultos de la comunidad hablante, que entienden que se trata de una especie de juego (y el juego solo es juego sólo en la medida en que se entiende como tal): "El receptor escrito es el destinatario totalizante dela enunciación, aquel que percibee doblejuego oralidad/escritura" (M alverde, 1985-1986: 79). Similar observación hace Rodríguez (1966: 13).

Esta situación da cuenta también, desde otro punto de vista, del carácter profundamente sal udable de la antipoesía parriana, pues procede de un manejo intelectualizado, pero internalizado, del libre juego de las posibilidades expresivas de la lengua nacional:

La antipoesía, con la excepción de algunos textos de Poemas y antipoemas, es una empresa de gran salud que libera a la poesía de ese campo de concentración enfermizo (donde no hay risa, humos, parodia, ironía) edificado por la "trascen dencia vacua", la "metafísica cubierta de amapolas", propia de una parte de la poesía moderna, o el construido por el compromiso político de la parte restante, que reviste de una idéntica gravedad y una moral, también, enferma (Rodríguez, 1966: 30). 
El texto, de hecho, siendo escrito, por un lado evoca la oralidad y por otro asume los rasgos de ésta que funcionalmente son pertinentes al sentido que quiere encarnar, con lo cual, de paso, se inserta, en lo cultural, como búsqueda y expresión de la identidad del autor, plenanente miembro de su cultura, y, finalmente, resolviendo las contradicciones que se hubieran encontrado si los sentidos mencionados se hubieran expresado sólo como hacer ora/tradicional o bien desde la lejanía de la mera cultura letrada. M alverde lo resume magistralmente:

La polaridad se resuelve en el texto, cuyo discurso escrito evoca la palabra hablada, en el que la cultura popular se introduce en el espacio de la cultura oficial por vía de la escritura que, por así decirlo, la formaliza (M alverde, 1985-1986: 88).

A hora bien, esteentronque de Parra con la cultura popular y con la oralidad, que según hemos visto alcanza estatus funcional, no se da en un vacío cultural. Primero, según ya hemos anotado, se da en la lengua castellana, en la tradición viva. Tiene también, por decirlo así, nombre y apellido: Chillán, por cierto Chillán Viejo, el barrio de Villa Alegre. Este espacio tan acotado, que se expresa en castellano, es el centro vital de la identidad del poeta. Sólo en castellano y desde C hillán, Nicanor Parra puede ser N icanor Parra, esté donde esté:

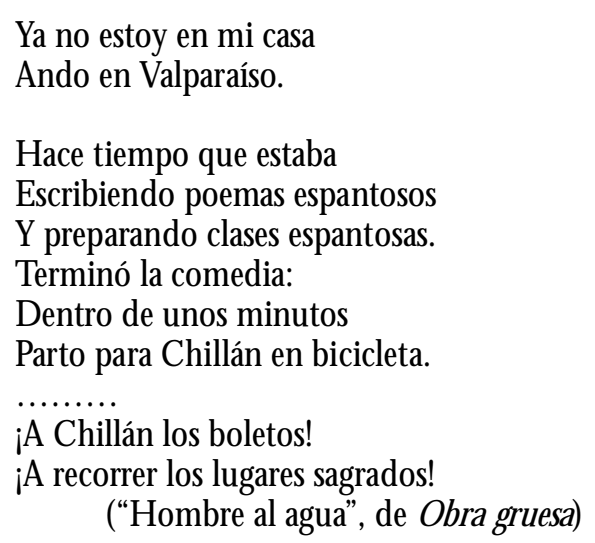

5. H abrá de resultar relevante, ahora, examinar cómo se ve expresando todo esto en la obra poética propiamente tal de Parra. M i planteamiento es el siguiente: $\mathrm{N}$ icanor Parra encuentra, vive y expresa su identidad en el lenguaje, en su condición de hablante arraigado de la lengua castellana chilena. Los propios "Iugares sagrados" al canzan su condición de tales, esto es, su carácter generador y asegurador de identidad, a través del lenguaje, 0 , quizás mejor, imbricados en el hablar concreto del poeta. 
Esta maduración de identidad no ha ocurrido ni espontáneamente ni de un día para otro. $\mathrm{H}$ a sido un proceso difícil y lento. En una primera época (en C ancionero sin nombre, 1937, aquel libro queel poeta oculta como se ocultaban antes los hijos mongólicos o deformes), Parra, de algún modo, mira y se mira desde fuera su mundo, y el lenguaje es también un instrumento ajeno que sólo menciona, o peor aun retoriza, sin encarnar, hechos, lugares, sentimientos:

El poeta está distraído de sí mismo, de la realidad, y el lenguaje, en lugar de revelar lo real, lo oculta o lo manipula a la manera de un ilusionista: muestra los objetos para luego, frente a nuestros propios ojos, evaporarlos (M orales, 1972: 25).

En su madurez, en cambio, el lenguajees el poeta mismo, su mismo mundo, que se reconoce, se delimita y se expresa. Es como si C hillán Viejo, el barrio de Villa Alegre, su gente y sus modos de comunicarse se embebieran como totalidad unitaria en el poeta, se encarnaran en su voz. En esemomento, en el despertar dela "antipoesía", N icanor Parra pudo decir para siempre, cual don Q uijote, "yo séquien soy". D esdeese momento, N icanor Parra puede hablar desdeC hillán para el mundo. C hillán, lugar sagrado, es el territorio del lenguaje.

Es relevante anotar aquí que la noción de "antipoesía", pese a su nombre engañoso, es una noción central para entender el proceso de asunción de una identidad vía lenguaje en $\mathrm{N}$ icanor Parra. Como fundamentadamentelo ha establecido I ván Carrasco (1990), la antipoesía no es un proceso de rebel día gratuita, sino que es una actitud que tiene raíces profundas en vertientes del pensamiento científico y filosófico moderno, y da como resultado el hecho de que "desde su particular ámbito de trabajo, N icanor Parra ha contribuido a colocar bases para una teoría asimétrica del cosmos" (p. 17). El antipoema resulta ser, sobre todo, una construcción de lenguaje, dondela incorporación internalizada dela lengua coloquial, como contrapartede la retórica culta tradicional, escomponente de la fibra íntima del texto:

El antipoema es... una imagen inversa del poema, pero no regida por una ley total de simetría, sino, al parecer, por una fuerza asimétrica (transformadora, desintegradora, deformante) de particular intensidad (Id.).

6. Ya he señalado que confrontar las reflexiones anteriores con textos poéticos concretos de Nicanor Parra puede ser aclarador e ilustrativo. Para cerrar este trabajo, consideraremos solamente dos poemas que tienen en común una explícita referencia a Chillán: uno de 1939, "Epopeya de C hillán" (publicado en la revista SECH , 1939, y recogido en Araya, 2000, pp. 103-104), y uno de 1954, "H ay un día feliz" (de Poemas y antipoemas, recogido luego en Obra gruesa, 
1969, pp. 20-22), "una de las más evidentes manifestaciones de la presencia del pueblo natal en su poesía" (Araya, 2000: 58). Para facilitar la lectura, ambos poemas se entregan en un apéndice.

La "Epopeya de Chillán" es, básicamente, un elogio retórico de la ciudad, concebida "literariamente", esto es mediante acumulación de tópicos, como un lugar donde todo es idílico y, por ende, irreal. Así, el "raudo viento azul del otoño" nos anuncia que Chillán existe "como una rosa blanca", como "una alta viña de nomeolvides", en un primaveral "abril celeste" y, aunque el agua se le vante "como un cisnefurioso", se insiste en que en Chillán "no pasa nada", sino "solamente todo", es decir, Chillán es el reino de la generalización, "correcta de lucero inmaculada frente", donde los campesinos se tornan en "el hortelano alegre" y donde los estudiantes, "como cansados ruiseñores", se dedican a estudiar las flores nativas. Lo más significativo es que el lenguajemismo, insistamos, "literario", apoya con energía esta actitud, engolado hasta lo inverosímil, pues Chillán se ve como "un toro con su clavel al cuello", como "Iuna y aún turbio diamante, derramándote sobre la ciudad como un sauce". Está claro: tanto elogio generalizador desdibuja la realidad y la convierte en mero tópico, por mucho que el poeta asegure que "voy a pasar la vida recordándote siempre", pues "aquí todo una llama, que aquí nada ceniza" y conjura "que se levante el fuego como un caballo de oro, que aquí no pasa nada, que puramente todo". Ese "todo" que pasa en ese C hillán retorizado es tan amplio, que ese C hillán no es el Chillán entrañable que conocemos y que añoramos, así como ese autor que ha engolado la voz no es el $\mathrm{N}$ icanor Parra queleemos y releemos con afecto agradecido. El "lenguaje de poema", de que habló J orge Guillén (1961), ha enmascarado hasta lo irreconocible el verdadero "Ienguaje poético".

D iametralmente opuesto es lo que sucede con el poema "H ay un día feliz". Aquí el poeta habla sólo de sí mismo evocando un Chillán personal e irrepetible. Así como la "Epopeya de Chillán" es un elogio retórico de Chillán que privilegia lo típico, "H ay un día feliz" es un ingreso a lo más auténtico y lo más real del espacio chillanejo como íntima morada humana, por la vía de la lengua castellana en su versión más asentadamente chilena, donde, por cierto, el componente retórico es esencial, pero asumido desde esa misma chilenidad.

D esde el inicio, el poema se abre con un tono que quiere ser explícitamente lírico, en el sentido tradicional intimista del término. El Chillán presente y real se ve ahora como una aldea donde "todo está en su lugar" no tanto por las observaciones objetivas sino por la lógica de la evocación. Además, las cosas que están en su lugar son "las golondrinas en la torre más alta de la iglesia", "el caracol en el jardín" y "el musgo en las húmedas manos delas piedras", donde se reconoce "la mirada celeste de mi abuela". Y dentro de esta lógica se mencionan 
hechos memorables de la del pasado personalizado: "el correo en la esquina dela plaza y la humedad en las murallas viejas". El tono ha sido casi desmedidamente sentimental, pero precisamente ahí aparece el verdadero $\mathrm{N}$ icanor Parra, el poeta que se apropia de su objeto a través de su lengua; de hecho, cuando el texto parece desmandarse, el poeta se vuelve a su coloquio chileno y se reformula: "¡Buena cosa, D ios mío!; nunca sabe uno apreciar la dicha verdadera”. Luego cae otra vez en el sentimentalismo (pero un sentimentalismo verdaderamente sentido), pero una vez más se reformula, graciasal giro del coloquio: "vamospor parte, no sé bien qué digo, la emoción se me sube a la cabeza". Y volvemos a la mención de "hechos memorables" de ese pasado chillanejo: las ovejas que vuelven al establo, el ruido del mar y las hojas de los árboles, todo tan individualizado, que las ovejas son saludadas personalmente y las hojas enumeradas, situación absurda si nuevamentelo coloquial no pusiera las cosas en su sitio, pues después de esas salidas solo se pone la cuña de un paréntesis magistral: "perfectamente bien", o sea, como si el poeta nos dijera "yo sé por dónde voy". Pero eso no es todo. Ese C hillán evocado como la morada concreta de lo humano, es el lar, la morada de la familia: padre, madre, hermanos, perro, vino y un inexplicable ruiseñor encima da la mesa, todo difuminado por el paso del tiempo, pero reconocido como gusto y aroma íntimos. Recapitulemos: este Chillán no es un objeto de retórica generalizante como en "Epopeya de Chillán"; este Chillán de "H ay un día feliz" es un objeto singular y concreto de recuerdo vívido. El pie forzado del empalago retórico nos aleja del Chillán de la "epopeya"; el lirismo sentimental del díafeliz nos entrega un momento personal hecho poema, o si se quiere, antipoema, sólido y entrañable, donde un Chillán de verdad se hace poema por la vía de la misma retórica, pero vitalizada por la internalización magistral de la lengua castellana en su versión chilena corriente, vital y productiva, tan diferente de esa "lengua chilena" fosilizada del facilismo folklórico. Sencillamente, el "lenguaje poético" ha cuajado en "lenguaje de poema". El verdadero territorio del poeta es su lengua.

\section{REFEREN CIAS BIBLIOGRAFICAS}

Araya, Juan Gabriel. 2000. Nicanor en Chillán. Concepción: Ediciones U niversidad de Bío-Bío.

Borges, Jorge Luis. 1966. Discusión. Buenos Aires: Emecé.

Campaña, Antonio. 1995. Poeśa y situación de N icanor Parra. Santiago: Ediciones del Instituto de Estudios Poéticos.

Carrasco M., Iván. 1990. Nicanor Parra: la escritura antipoética. Santiago: Talleres de la Editorial Universitaria.

Guillén, Jorge. 1961. Lenguaje y poeśa. M adrid: Revista de 0 ccidente. 
M alverde D isselkoen, N . Ivette. 1985-86. "La interacción escritura-oralidad en el discurso carnavalesco de los Sermonesy prédicasdel Cristo deElqui", en Acta Literaria $\mathrm{N}$ ㅇ 1011, pp. 77-89.

- 1988. "El discurso de carnaval y la poesía de Nicanor Parra", en Acta Literaria № 13, pp. 83-92.

M orales T., Leonidas. 1972. La poeśa de N icanor Parra. Santiago: coedición U niversidad Austral de Chile y Editorial Andrés Bello.

O stria, M auricio. 1988. Escritos de varia lección. Concepción: Ediciones Sur.

Rodríguez, M ario. 1996. O rbita deN icanor Parra. Ediciones Universidad de Concepción; Serie Cuadernos del Bío-Bío № 6 .

\section{APENDICE: DOS TEXTOS DE NICANOR PARRA}

(1) Epopeya de Chillán (1939)

$Q$ ue se levante el raudo viento azul del otoño Q ue aquí no pasa nada, que puramente todo. Chillán, C hillán existe como una rosa blanca Sobre mi corazón húmedo y sin palabras. Chillán, como una alta viña de nomeolvides Eternamente pura sobre mi alma existe. $Q$ ue se levante el agua como un cisne furioso $\mathrm{Q}$ ue aquí no pasa nada que solamente todo.

En la empinada torre de la montaña canta Como un pájaro suelto la nieve y la mañana, Chillán, igual que un toro con su clavel al cuello Corriendo como un río como sangre lo siento. Su caracol de plata retumba en mis oídos $Y$ en mis ojos de sombra se establece el rocío. Chillán no está vencido, C hillán laurel alzado Como en el verde campo los gentiles caballos. $Q$ ue se levante el trueno vivo de los tambores $Y$ el hortelano al egre que se levante entonces. C hillán en cada gancho de cada lirio libra C omo la espada abierta de la noche sombría. Q ue la naranja surge de su capullo de oro Q ue aquí no pasa nada que eternamente todo. Levántese el anillo de nuestra mano y sea Levantado el brillante mineral de la tierra.

Chillán igual que un trébol o como un mar se extiende Correcta de lucero inmaculada frente.

Aún te veo luna y aún turbio diamante 
D erramándote sobre la ciudad como un sauce.

Y así como te veo marfil volando

Así te tiene preso mi pecho de corsario.

Q ue se levante pido la piedra como un ángel

Y la sin par abeja pido que se levante.

Chillán, Chillán el pueblo de la noche serena

Dilatada y sencilla como una floresta.

En tus jardines como cansad os ruiseñores

Están tus estudiantes estudiando tus flores.

Chillán, abril celeste y otra cosa celeste.

Voy a pasar la vida recordándote siempre

D e ti nació la fina raigambre de la hoja

Y el hocico sangriento de la ruda paloma.

$Q$ ue se levante entonces como una bestia el día

Q ue aquí todo una llama que aquí nada ceniza.

Q ue se levante el fuego como un caballo de oro

Q ue aquí no pasa nada que puramente todo.

(2) H AY UN DíA FELIZ (1954)

A recorrer me dediqué esta tarde

Las solitarias calles de mi aldea

Acompañado por el buen crepúsculo

Q ue es el único amigo que mequeda.

Todo está como entonces, el otoño

Y su difusa lámpara de niebla,

Sólo que el tiempo lo ha invadido todo

Con su pálido manto de tristeza.

N unca pensé, creédmelo, un instante,

Volver a ver esta querida tierra,

Pero ahora que he vuelto no comprendo

Cómo pude alejarme de su puerta.

$\mathrm{N}$ ada ha cambiado, ni sus casas blancas,

$\mathrm{N}$ i sus viejos portones de madera.

Todo está en su lugar, las golondrinas

En la torre más alta de la iglesia;

El caracol en el jardín, y el musgo

En las húmedas manos de las piedras.

$\mathrm{N}$ o se puede dudar, este es el reino

Del cielo azul y de las hojas secas

En donde todo y cada cosa tiene

Su singular y plácida leyenda:

$H$ asta en la propia sombra reconozco

La mirada celeste de mi abuela. 
Estos fueron los hechos memorables Q ue presenció mi juventud primera, El correo en la esquina de la plaza Y la humedad en las murallas viejas. ¡Buena cosa, Dios mío!; nunca sabe Uno apreciar la dicha verdadera,

Cuando la imaginamos más lejana

Es justamente cuando está más cerca.

Ay de mí, iay de mí!, algo me dice

Q ue la vida no es más que una quimera;

Unailusión, un sueño sin orillas,

Una pequeña nube pasajera.

Vamos por partes, no sé bien qué digo,

La emoción se me sube a la cabeza.

Como ya era la hora del silencio

Cuando emprendí mi singular empresa,

Una tras otra, en oleaje mudo,

Al establo volvían las ovejas.

Las saludé personalmente a todas

$Y$ cuando estuve frente a la arboleda

Q ue alimenta el oído del viajero

Con su inefable música secreta

Recordé el mar y enumerélas hojas

En homenaje a mis hermanas muertas.

Perfectamente bien. Seguí mi viaje

Como quien de la vida nada espera.

Pasé frente a la rueda del molino,

$M$ e detuve delante de una tienda:

El olor del café siempre es el mismo, Siempre la misma luna en mi cabeza;

Entre el río de entonces y el de ahora

$\mathrm{N} o$ distingo ninguna diferencia.

Lo reconozco bien, este es el árbol

Q ue mi padre plantó frente a la puerta

(Ilustre padre que en sus buenos tiempos

fuera mejor que una ventana abierta).

Yo me atrevo a afirmar que su conducta

Era un trasunto fiel de la Edad M edia

Cuando el perro dormía dulcemente

Bajo el ángulo recto de una estrella.

A estas alturas siento que me envuelve

El delicado olor de las violetas 
Q ue mi amorosa madre cultivaba

Para curar la tos y la tristeza.

Cuánto tiempo ha pasado desde entonces

N o podría decirlo con certeza;

Todo está igual, seguramente, el vino

Y el ruiseñor encima de la mesa,

$M$ is hermanos menores a esta hora

D eben venir de vuelta de la escuela.

¡Sólo que el tiempo lo ha borrado todo

como una blanca tempestad de arena! 